\title{
Miller-Dieker syndrome resulting from rearrangement of a familial chromosome 17 inversion detected by fluorescence in situ hybridisation
}

\author{
Helen M Kingston, David H Ledbetter, Pam I Tomlin, K Lorraine Gaunt
}

\begin{abstract}
We report a case of Miller-Dieker syndrome (MDS) owing to an unbalanced rearrangement of a familial pericentric inversion of chromosome 17 (inv(17) (p13.3q25.1)). In addition to lissencephaly and the facial features of MDS, the affected child had other congenital malformations consistent with distal $17 q$ duplication. Initial cytogenetic analysis failed to show any abnormality and fluorescence in situ hybridisation (FISH) studies confirmed the $17 p$ deletion in the proband and identified the chromosome 17 inversion in his mother. FISH studies were performed in other relatives and enabled first trimester prenatal diagnosis by chorionic villus sampling in a subsequent pregnancy of the proband's mother. These findings underline the value of FISH in the investigation of MDS families.

( 7 Med Genet 1996;33:69-72)
\end{abstract}

Key words: Miller-Dieker syndrome; fluorescence in situ hybridisation; chromosome 17 inversion.

Lissencephaly is a severe brain malformation characterised by a smooth cerebral surface (agyria-pachygyria) and abnormal neuronal migration resulting in profound mental retardation, seizures, and other neurological abnormalities. ${ }^{1}$ Classical type I lissencephaly may occur as an isolated abnormality or in association with dysmorphic features in MillerDieker syndrome (MDS). ${ }^{23}$ The characteristic craniofacial appearance in MDS consists of bitemporal hollowing, prominent forehead and furrowed brow, short nose with anteverted nares, prominent upper lip, and small jaw. ${ }^{45}$ Cardiac defects and other malformations may

Deletions of chromosome $17 \mathrm{p} 13.3$ can be shown in the majority of MDS patients. About $50 \%$ of cases have a visible deletion detected by high resolution cytogenetic analysis. ${ }^{5}$ The remainder can be detected by molecular methods such as RFLP analysis or somatic cell hybrid analysis ${ }^{5-8}$ and more recently by fluorescence in situ hybridisation (FISH).${ }^{910} \mathrm{~A}$ gene containing $\mathrm{G}$ protein $\beta$ subunit-like repeats designated lissencephaly-1 (LIS-1) has been identified in this region, and non-overlapping deletions affecting either the $5^{\prime}$ or $3^{\prime}$ end of the gene found in two patients with
MDS identify LIS-1 as a candidate for the disease gene. ${ }^{11}$ Deletions including LIS-1 have been reported in $92 \%$ of Miller-Dieker probands and $38 \%$ of classical ILS cases. ${ }^{12}$ Homology between the sequence of the $45 \mathrm{~K}$ subunit of platelet activating factor (PAF) acetylhydrolase present in bovine cerebral cortex and the protein encoded by the LIS-1 gene has been reported. ${ }^{13}$

Many cases of MDS are sporadic, but familial cases are well documented, including the families originally described by Miller ${ }^{2}$ and Dieker et $a .^{3}$ Recurrence within families is always because of a balanced parental chromosome rearrangement. ${ }^{14}$ We report a case of MillerDieker syndrome owing to a familial inversion of chromosome 17 detected by FISH analysis which enabled investigation of relatives and prenatal diagnosis in a subsequent high risk pregnancy.

\section{Case report (fig 1)}

The proband IV $\cdot 2$ was born at term following a pregnancy complicated by intrauterine growth retardation and polyhydramnios from 20 weeks' gestation. Prenatal ultrasonography indicated short limbs and a cystic mass in the right hypochondrium, thought to be a dilated gall bladder. Chromosome analysis of cultured amniocytes showed an apparently normal male karyotype.

At delivery the birth weight was $2300 \mathrm{~g}$ and multiple congenital anomalies were detected consisting of rhizomelic shortening of the limbs, short digits, proximally placed thumbs, partial 2-3 syndactyly of the toes bilaterally, cleft of the soft palate, glandular hypospadias, bilateral undescended testes, and sacral tail. Dysmorphic craniofacial features included prominent forehead, large anterior fontanelle, three hair whorls on the crown, a short neck with a low posterior hairline and redundant skin, short and unusually shaped palpebral fissures, small ears, and small jaw (fig 2). Postnatally the proband developed laryngeal stridor and growth parameters for length, weight, and OFC followed the $3 \mathrm{rd}, 3 \mathrm{rd}$, and 10 th centiles respectively. Convulsions started at the age of 6 months, at which time the EEG showed clusters of raised voltage high frequency rhythms, raising the possibility of lissencephaly. Very high amplitude activity increasing in frequency from theta through alpha to beta activity has been described in lissencephaly. ${ }^{15} \mathrm{CT}$ brain scan also be present.

\footnotetext{
Received 20 June 1995 Revised version accepted for publication

19 September 1995

Paediatric Neurology Sharoe Green Lane Preston PR2 4HT, UK

Regional Genetic
Service, St Mary's
Hospital, Hathersage
Road, Manchester
M13 0JH, UK
H M Kingston
K L Gaunt
Diagnostic
Development Branch,
National Centre for
Human Genome
Research, National
Institutes of Health,
Bethesda, MD 20892,
USA
D H Ledbetter
Paediatric Neurology
Department, Preston
Royal Hospital,
Sharoe Green Lane,
Preston PR2 4HT, UK
P I Tomlin
Correspondence to:
Dr Kingston.
Received 20 June 1995
Revised version accepted
for publication
19 September 1995
}




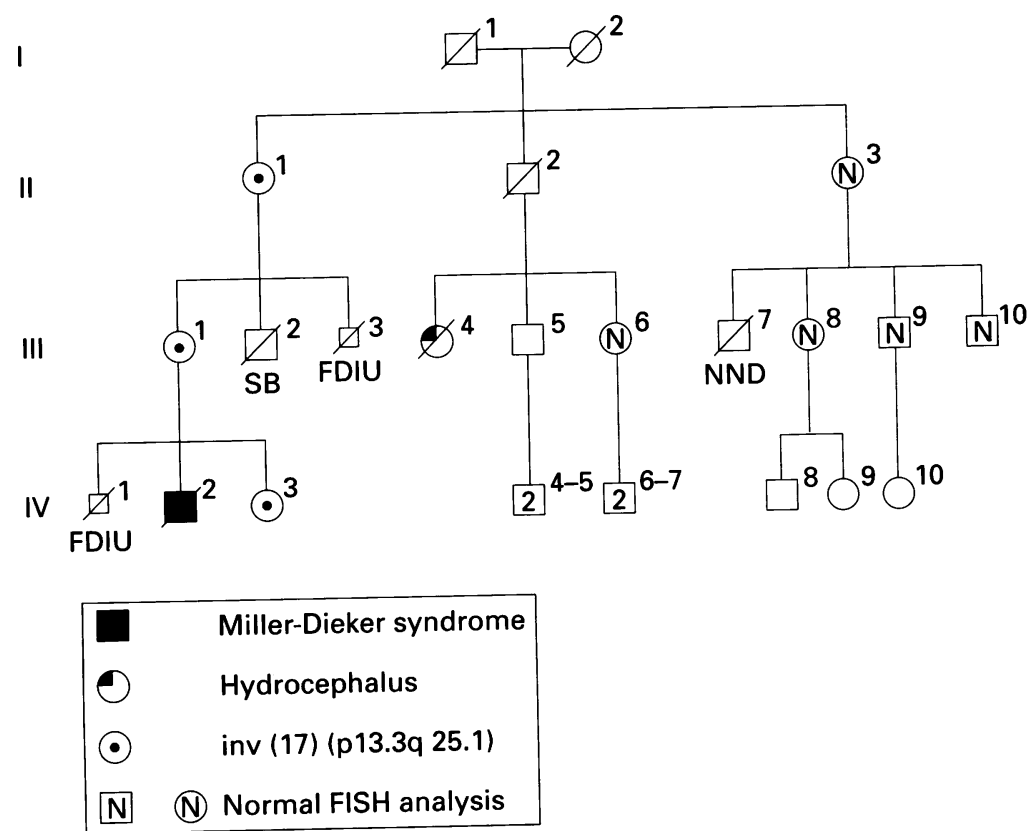

Figure 1 Pedigree of the family indicating several cases of fetal death in utero (FDIU), Figure 1 Pedigree of the family indicating several cases of fetal see family report.

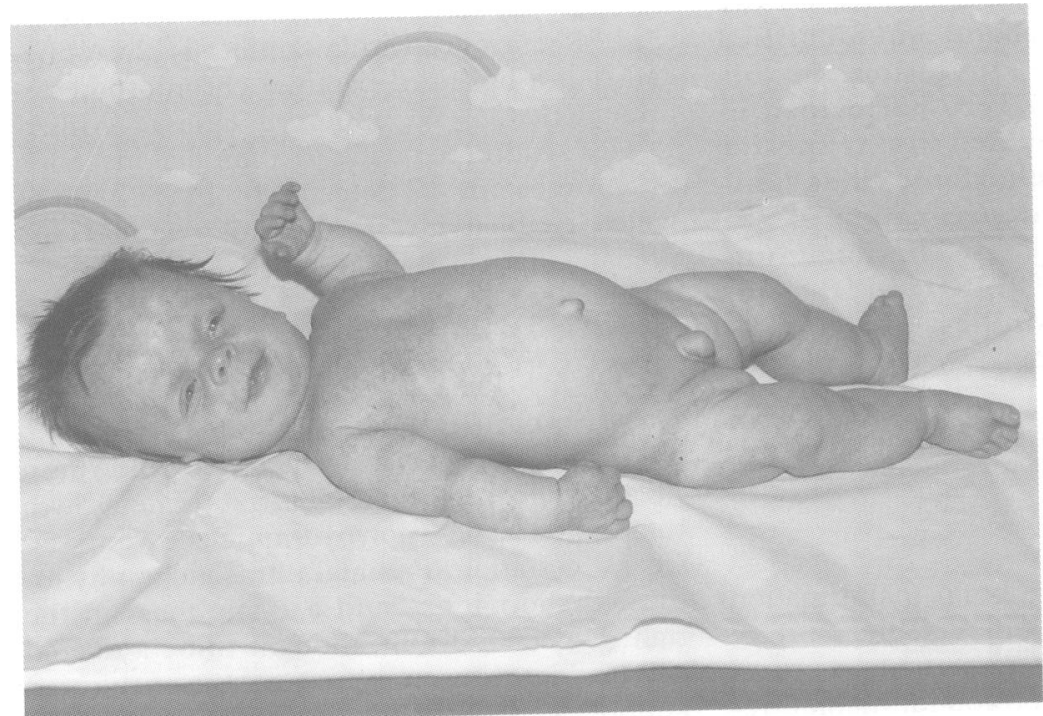

Figure 2 The proband aged 4 months.

showed type I lissencephaly, absent corpus callosum, and dilated ventricles (fig 3). A clinical diagnosis of Miller-Dieker syndrome was made. Subsequent developmental progress was extremely limited, and after recurrent episodes of aspiration pneumonia and status epilepticus the proband died at the age of 2 years 7 months. No necropsy was performed.

\section{Family history}

There were several cases of intrauterine death, stillbirth, or neonatal death in the extended family. The first pregnancy of the proband's mother (III-1) had resulted in a fetal death in utero at 22 weeks' gestation. No obvious external abnormalities were documented in the macerated male fetus. The proband's grandmother (II-1) had an unexplained male stillbirth and a fetal death in utero in late pregnancy. Two other maternal relatives had

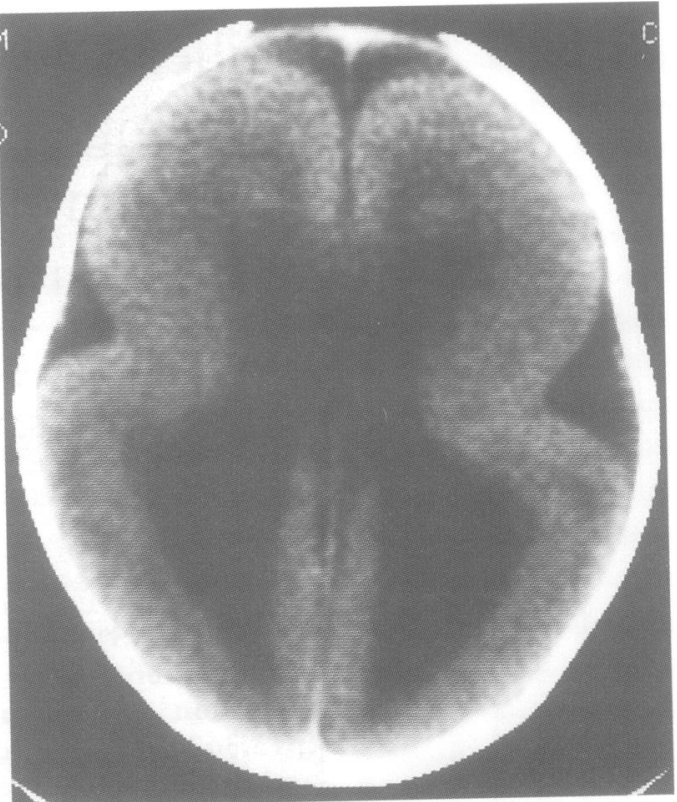

Figure $3 C T$ brain scan of the proband showing type 1 lissencephaly with dilated ventricles.

respectively an infant death owing to hydrocephalus and a neonatal death of unknown cause. No further information was available for these four latter cases.

\section{Cytogenetic studies}

Banded chromosome analysis in the proband and his mother failed to show any abnormality of chromosome 17. FISH studies were performed on peripheral blood lymphocytes with a chromosome 17 centromeric alpha satellite probe (D17Z1) and a set of three overlapping cosmids (c197-2, c197-4, and c197-9) from the MDS critical region of $17 \mathrm{p} 13.3 .^{10}$ A $17 \mathrm{p}$ deletion was detected in the proband and a pericentric inversion of chromosome 17 in the mother (fig 4). Subsequent $G$ banded chromosome analysis confirmed a $46, \mathrm{XX}$, inv(17)(p13.3q25.1) karyotype in the mother. The proband's karyotype can thus be designated 46,XY,rec(17), dup q,inv(17) (p13.3q25.1)mat. FISH studies performed in six other relatives identified the presence of the pericentric inversion only in the proband's grandmother. It is possible that II. 2 also carried the mutation and III. 5 who declined testing remains at risk.

First trimester chorionic villus sampling was performed during the third pregnancy of the proband's mother. Chromosome analysis showed an apparently normal 46,XX karyotype, but FISH analysis on both direct and cultured villus preparations identified the presence of a balanced pericentric inversion of chromosome 17. Second trimester ultrasonography showed no fetal abnormalities and a healthy female infant has subsequently been born. Presence of the balanced pericentric inversion was confirmed postnatally by FISH analysis. 

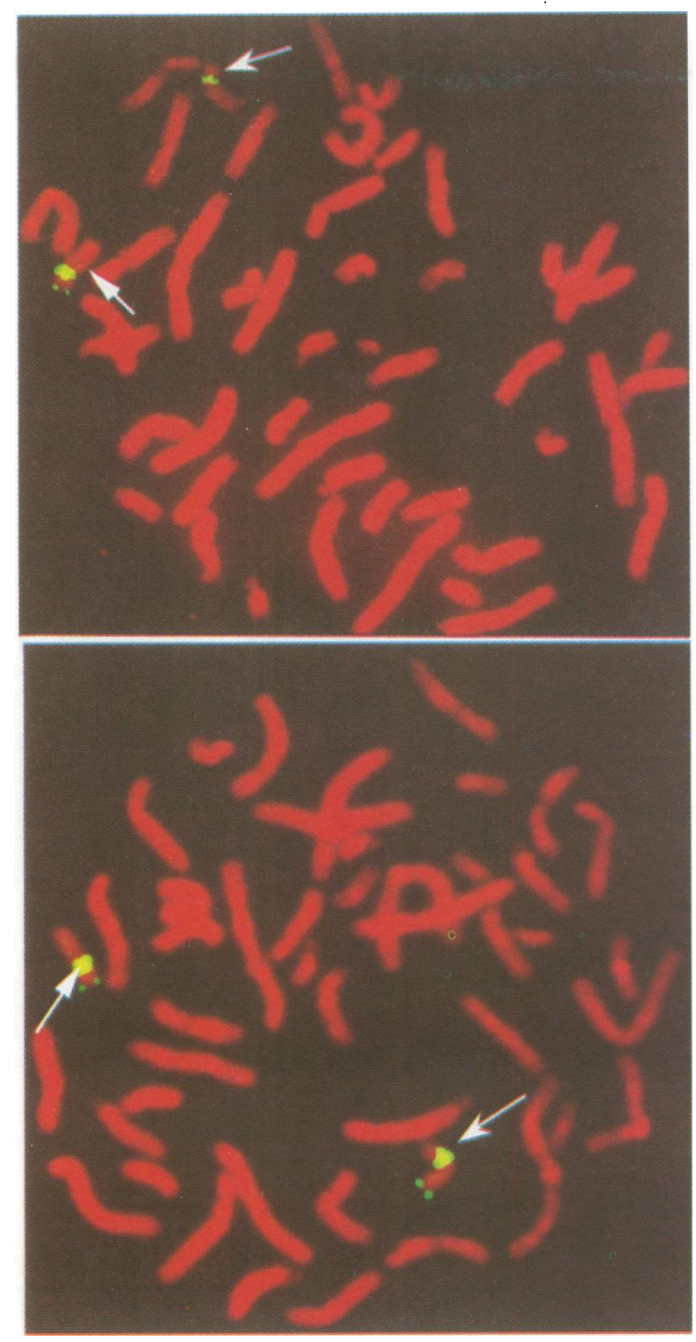

Figure 4 (Top) FISH analysis of metaphase chromosomes from the proband. The normal chromosome 17 displays both centromeric alpha satellite (arrowed) and MDS cosmid probe signals. The abnormal chromosome 17 displays only a centromeric probe signal (arrowed) indicating a deletion at 17p13.3. (Bottom) FISH analysis of metaphase chromosomes from the proband's mother. Both chromosomes 17 display signals with the centromeric alpha satellite probe (arrowed). The normal chromosome 17 displays a signal on $17 p$ with the MDS cosmid probe. The abnormal chromosome 17 displays a hybridisation signal on the distal long arm with the MDS cosmid probe resulting from a pericentric inversion: $46, X X$, inv (17) $(p 13.3 q 25.1)$.

\section{Discussion}

Structural chromosome abnormalities resulting in Miller-Dieker syndrome include sporadic terminal deletions and ring chromosome $17,{ }^{1416-18}$ as well as a variety of unbalanced products of reciprocal translocations. ${ }^{1419}$ Variation in phenotype in the latter group may be attributed to the presence of different duplicated segments in addition to the $17 \mathrm{p}$ monosomy. One other family with Miller-Dieker syndrome owing to rearrangement of a pericentric inversion of chromosome 17 has been reported, ${ }^{20}$ although this involved a larger unbalanced segment that could be identified by chromosome banding analysis. Additional features representing distal $17 \mathrm{q}$ duplication ${ }^{2122}$ were present in the affected offspring. In our case additional features consisted of frontal bossing, broad midface, narrow palpebral fis- sures, cleft palate, multiple abnormal hair whorls, short neck, short proximal limbs, short digits, 2-3 syndactyly of the toes, sacral tail, hypospadias, and bilateral undescended testes. There was no polydactyly, congenital heart disease, or evidence of renal anomalies. The rudimentary tail present in our case and those of Greenberg et $a l^{20}$ has also been observed in another MDS patient, ${ }^{23}$ but not in cases with duplication of $17 \mathrm{q}$. Caine et a ${ }^{4}$ described calcified gallstones as a previously unreported feature of $17 \mathrm{q}$ duplication and it is interesting that our case had a cystic mass in the right hypochondrium detected by prenatal ultrasonography thought to represent a dilated gall bladder.

FISH analysis is a valuable tool in the clarification of subtle reciprocal rearrangements ${ }^{25}{ }^{26}$ and has been used to identify cryptic and half cryptic translocations in several cases of Miller-Dieker syndrome. ${ }^{927-29}$ The study of Kuwano et al included a half cryptic $3 \mathrm{q} ; 17 \mathrm{p}$ and a full cryptic $8 \mathrm{q} ; 17 \mathrm{p}$ translocation. The case of Alvarado $e t \mathrm{al}^{27}$ represented a full cryptic $17 p ; 19 q$ translocation, while those of Kohler et $a l^{28}$ and Brecevic $e t a l^{29}$ both represented half cryptic $9 p ; 17 p$ translocations. In our case initial conventional cytogenetic analysis did not identify any chromosome 17 abnormality in the proband or his mother, even though the family history was highly suggestive of a familial chromosome rearrangement and the presence of an abnormality was suspected. Definitive diagnosis of Miller-Dieker syndrome was made by FISH analysis which showed a $17 \mathrm{p}$ deletion in the proband. A pericentric inversion of chromosome 17 was detected in the proband's mother and grandmother. FISH analysis was offered to other relatives at risk, and enabled first trimester prenatal diagnosis in a subsequent pregnancy of the proband's mother. A fetus with the balanced pericentric inversion was detected, and a healthy infant has subsequently been born.

It is clearly important to distinguish between sporadic $17 \mathrm{p}$ deletions and those resulting from cryptic familial rearrangements which have a high recurrence risk in order to provide accurate genetic counselling. In our case the availability of a definitive first trimester prenatal diagnosis was an important factor in the couple's decision to embark upon a further pregnancy. The value of FISH for diagnosis, investigation of relatives, and prenatal diagnosis in this family supports the recommendation of Kuwano et $a l^{9}$ that FISH analysis should be performed in all parents of children with MDS resulting from submicroscopic deletions to detect subtle rearrangements associated with a high recurrence risk.

A permanent cell line of one of the balanced inversion carriers is available at St Mary's Hospital, Manchester via Dr H Kingston.

1 Dobyns WB. The neurogenetics of lissencephaly. Neurol Clin 1989;7:89-105.

2 Miller JQ. Lissencephaly in two siblings. Neurology 1963; 13:841-50.

3 Dieker H, Edwards RH, Zurhein G, Chou SM, Hartman HA, Opitz JM. The lissencephaly syndrome. Birth Defects 1969;2:53-64.

4 Jones KL, Gilbert EF, Kaveggia EG, Opitz JM. The MillerDieker syndrome. Pediatrics 1980;66:277-81. 
5 Dobyns WB, Curry CJR, Hoyme HE, Turlington L, Ledbetter DH. Clinical and molecular diagnosis of Miller-Dieker syndrome. Am $\mathcal{f}$ Hum Genet 1991;48: 584-94.

6 Schwartz CE, Johnson JP, Holycross B, et al. Detection of submicroscopic deletions in band 17 p13 in patients with the Miller-Dieker syndrome. Am $\mathcal{F}$ Hum Genet 1988;43: 597-604.

7 vanTuinen P, Dobyns WB, Rich DC, et al. Molecular detection of microscopic and submicroscopic deletions associated with Miller-Dieker syndrome. Am f Hum Genet 1988;43:587-96.

8 Ledbetter DH, Ledbetter SA, vanTuinen P, et al. Molecular dissection of a contiguous gene syndrome: frequent submicroscopic deletions, evolutionarily conserved sequences, and a hypomethylated "island" in the Millerquences, and a hypomethylated "island" in the Miller-
Dieker chromosome region. Proc Natl Acad Sci USA 1989; 86:5136-40.

9 Kuwano A, Ledbetter SA, Dobyns WB, Emanuel BS, Ledbetter DH. Detection of deletions and cryptic translocations in Miller-Dieker syndrome by in situ hybridization. Am f Hum Genet 1991;49:707-14.

10 Ledbetter SA, Kuwano A, Dobyns WB, Ledbetter DH. Microdeletions of chromosome $17 \mathrm{p} 13$ as a cause of isolated lissencephaly. Am F Hum Genet 1992;50:182-9.

11 Reiner O, Carrozzo R, Shen Y, et al. Isolation of a MillerDieker lissencephaly gene containing $G$ protein $\beta$-subunitlike repeats. Nature 1993;364:717-21.

12 Dobyns WB, Reiner O, Carrozzo R, Ledbetter DH. Lissencephaly. A human brain malformation associated with deletion of the LIS1 gene located at chromosome $17 \mathrm{p} 13$. fAMA 1993;270:2838-42.

13 Hattori $M$, Adachi $H$, Tsujimoto $M$, Arai $H$, Inoue $K$. Miller-Dieker lissencephaly gene encodes a subunit of brain platelet-activating factor. Nature 1994;370:216-8.

14 Stratton RF, Dobyns WB, Airhart SD, Ledbetter DH. New chromosomal syndrome: Miller-Dieker syndrome and monosomy 17p13. Hum Genet 1984;67:193-200.

15 Gastaut H, Pinsard N, Raybaud C, Aicardi J, Zifkin B. Lissencephaly (agyria-pachygyria): clinical findings and Lissencephaly (agyria-pachygyria): clinical findings and

16 Dobyns WB, Stratton RF, Parke JT, Greenberg F, Nussbaum RL, Ledbetter DH. Miller-Dieker syndrome: lissencephaly and monosomy 17p. F Pediatr 1983;102: $552-8$.

7 Carpenter NJ, Leichtman LG, Stamper S, Say B. An infant with ring 17 chromosome and unusual dermatoglyphs: new syndrome? f Med Genet 1981;18:234-6.

18 Sharief N, Craze J, Summers D, Butler L, Wood CBS Miller-Dieker syndrome with ring chromosome 17. Arch 66:710-2.

19 Berry R, Wilson H, Robinson J, et al. Apparent SmithLemli-Opitz syndrome and Miller-Dieker syndrome in family with segregating translocation $\mathrm{t}(7,17)(\mathrm{q} 34 ; \mathrm{p} 13.1)$ Am f Med Genet 1989;34:358-65.

20 Greenberg F, Stratton RF, Lockhart LH, Elder FFB, Dobyn WB, Ledbetter DH. Familial Miller-Dieker syndrom associated with pericentric inversion of chromosome 17 . Am ₹ Med Genet 1986;23:853-9.

21 Serotkin A, Stamberg J, Waber L. Duplication 17q mosaicism: an infant with features of Ellis-van Creveld syndrome. F Med Genet 1988;25:258-69.

22 Bridge J, Sanger W, Mosher G, et al. Partial duplication of distal 17q. Am f Med Genet 1985;22:229-35.

23 Daube JR, Chou SM. Lissencephaly: two cases. Neurology 1966;16:179-91.

24 Caine A, Knapton DM, Mueller RF, Congdon PJ, Haigh D. Duplication of distal $17 \mathrm{q}$ from a maternal translocation an additional case with some unique features. $7 \mathrm{Med}$ Gene 1989;26:577-89.

25 Ledbetter DH. Minireview; cryptic translocation and telomere integrity. Am F Hum Genet 1992;51:451-6.

26 Sullivan BA, Leana-Cox J, Schwartz S. Clarification of subtle reciprocal rearrangements using fluorescence in situ hybridisation. Am f Med Genet 1993;47:223-30.

27 Alvarado M, Bass HN, Caldwell S, Jamehdor M, Miller AA, Jacob P. Miller-Dieker syndrome. Detection of a cryptic chromosome translocation using in situ hybridisation in a family with multiple affected offspring. Am f Dis Child 1993;147:1291-4.

28 Kohler A, Hain J Muller U. Familial half cryptic translocation $\mathrm{t}(9 ; 17)$. F Med Genet 1994;31:712-4.

29 Brecevic L Binkert F, Boltshauser E, Schinzel A. Fluorescent in situ hybridisation detection of a balanced $t(9$ 17) translocation in the father of a child with lissencephaly and additional abnormalities. Dev Brain Dysfunct 1994;7 $147-54$. 